\title{
Maxillary Carcinosarcoma: A Case Report and Review of the Literature
}

\author{
${ }^{1}$ Ilson Sepúlveda, ${ }^{2}$ Michael Frelinghuysen, ${ }^{3}$ Cesar García, ${ }^{4} \mathbf{M}$ Loreto Spencer \\ ${ }^{5}$ Enrique Platín, ${ }^{6}$ Jaqueline Alarcon, ${ }^{7}$ David Ulloa
}

\begin{abstract}
We report on a patient who presented with pain and swelling to the left maxillary region of the face. A biopsy of the area was performed and subsequently diagnosed as maxillary carcinosarcoma (CCS). After reviewing the pathology results and the size of the tumor, it was decided that a radical dissection, followed by radiation therapy was the best option.
\end{abstract}

Keyword: Carcinosarcoma, Computed tomography, Sinonasal, Tumor.

How to cite this article: Sepúlveda I, Frelinghuysen M, García C, Spencer ML, Platín E, Alarcon J, Ulloa D. Maxillary Carcinosarcoma: A Case Report and Review of the Literature. Int J Otorhinolaryngol Clin 2014;6(3):114-117.

Source of support: Nil

Conflict of interest: None

\section{CASE REPORT}

We report on a 66-year-old male patient who presented to the ENT service without a significant clinic history. The patient exhibited swelling in the left maxillary region of the face and palatine area that began 2 months earlier. Clinically, a necrotic tumor mass was observed in the nasogenian folds and periphery of the oral and orbital cavity.

A CT was acquired demonstrating a large expansive, invasive and heterodense process on the left half-face.

${ }^{1,5}$ Professor, ${ }^{2,3}$ Radiation Oncologist, ${ }^{4}$ Physician Pathologist ${ }^{6}$ Dental Student, ${ }^{7}$ General Physician

${ }^{1}$ Department of Otolaryngology and Head and Neck Surgery General Hospitals of Concepción; School of Dentistry, Finis Terrae University, Chile

${ }^{2,3}$ Department of Oncology, General Hospitals of Concepción, Chile ${ }^{4}$ Department of Pathology, General Hospitals of Concepción, Chile

${ }^{5}$ Department of Oral and Maxillofacial Radiology, School of Dentistry, University of North Carolina, North Carolina, USA

${ }^{6}$ School of Dentistry, University of Concepción, Chile

${ }^{7}$ Department of School of Medicine, San Sebastián University Chile

Corresponding Author: Ilson Sepúlveda, Professor, Department of Otolaryngology and Head and Neck Surgery, General Hospitals of Concepción; School of Dentistry, Finis Terrae University, Chile Phone: 56412722749, e-mail: isepulvedaguilar@gmail.com
The mass seemed to originate from the maxillary region extending into the ipsilateral orbital, oral and nasal cavities (Figs 1 and 2). Postintravenous contrast injection, the mass was moderately enhanced revealing central necrotic areas (Figs 3 and 4).

The histopathology revealed fused cells with marked pleomorphism, atypical mitosis, myxoid degeneration and isolated multinucleated giant tumor cells. A sector showed an infiltrative superficial epithelial tumor with cords and nests; polygonal cell tumor involving the lateral margins (Fig. 5). The immunohistochemistry revealed a positive intense vimentin diffused in both components of the tumor, cytokeratin positive in isolated fused cells, positive diffuse in epithelial sector and negative for actin, desmin, CD 34 and S 100. In summary, the biopsy showed a malignant neoplasm with necrosis and characteristics of carcinosarcoma (CCS) (Figs 6 and 7).

Following review by the head and neck cancer committee that recommended radical excision of the tumor followed by radiation therapy. This recommendation was made based on the clinical findings, results of the biopsy and imaging studies. Also, the committee recommended enrollment of the patient in a pain management and palliative care program.

Subsequently a left maxillectomy was performed with orbital floor reconstruction. During surgery, infiltration of the orbital floor was noted, without apparent compromise of the orbital contents.

Conventional radiotherapy treatment consisted of a total dose of 66 Gy delivered to the affected area in 2 Gy increments during a 7-week period (Fig. 8). Following radiotherapy, an slight decrease in tumor size was noted. The patient reported pain, insomnia and a decrease in food intake consequently being referred to the pain and palliative care program.

\section{DISCUSSION}

Head and neck malignant neoplasms predominantly occur in the oral cavity, pharynx, ear, nose and larynx. Ninety to ninety-five percent of head and neck tumors correspond to squamous cell carcinomas. ${ }^{1,2}$ Sarcomas constitute less than $1 \%$ of all malignant neoplasms in the body including the head and neck region. Carcinosarcoma is rare and tends to be aggressive. It is a biphasic tumor 


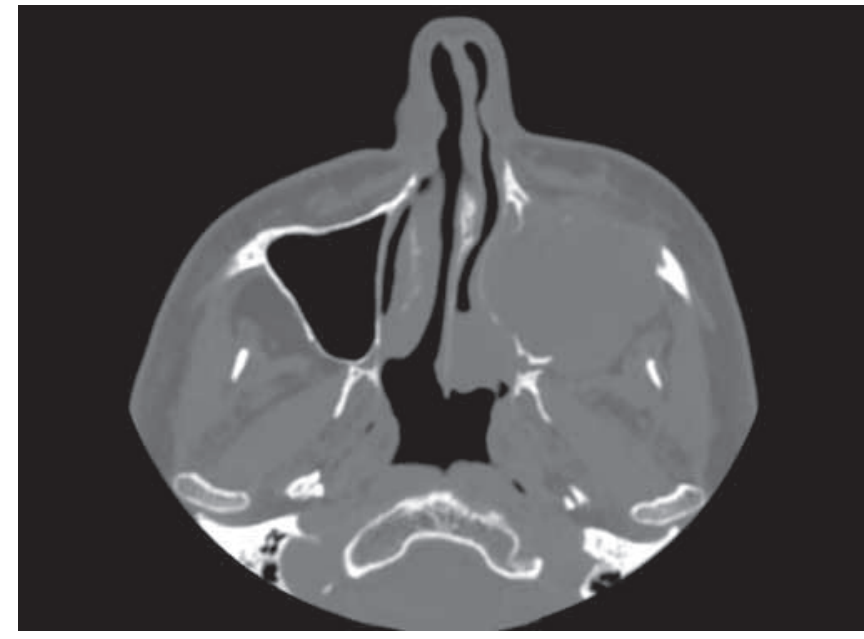

Fig. 1: Axial CT bone window, showing a destructive, expansive process eroding the maxillary sinus walls

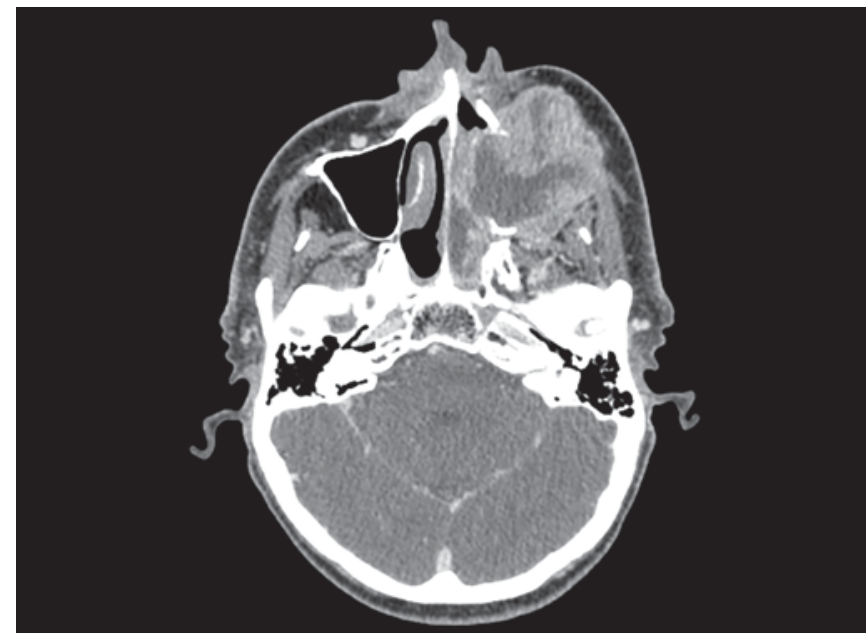

Fig. 3: Axial CT showing moderate enhancement after intravenous contrast, administration revealing areas of necrosis

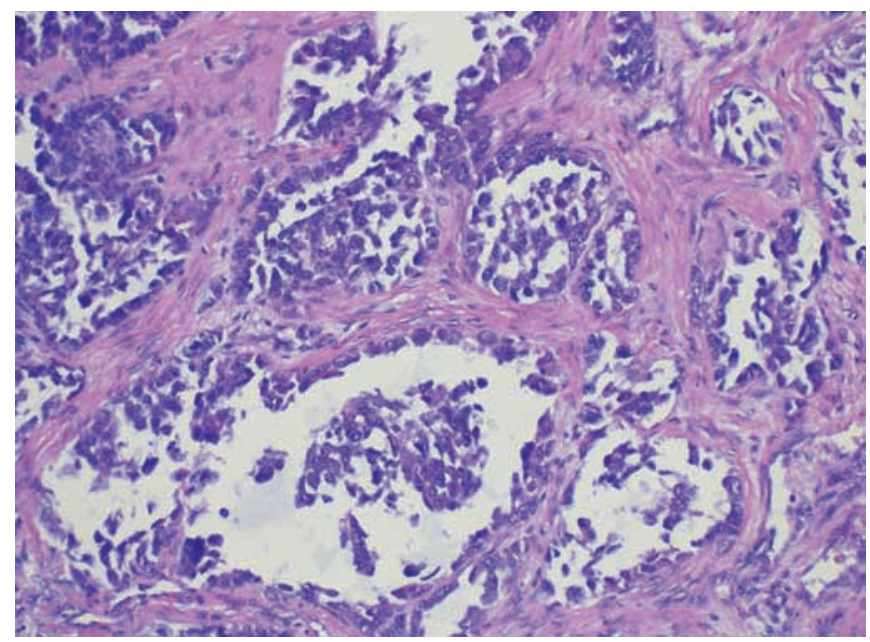

Fig. 5: HE stain

comprising both a malignant epithelial (carcinomatous) and mesenchymal (sarcomatous) components. ${ }^{3-6}$ It is more prevalent in men than women with a ratio of 11:1 most often occurring between the ages of 60 and 70 years.

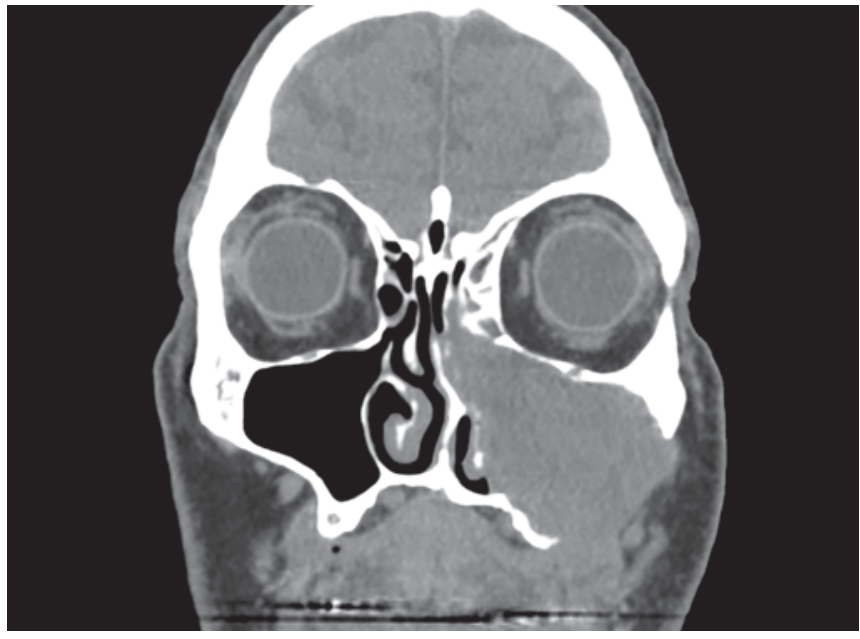

Fig. 2: Coronal CT soft tissues window demonstrating a heterodense maxillary mass compromising the subcutaneous muscle and fat

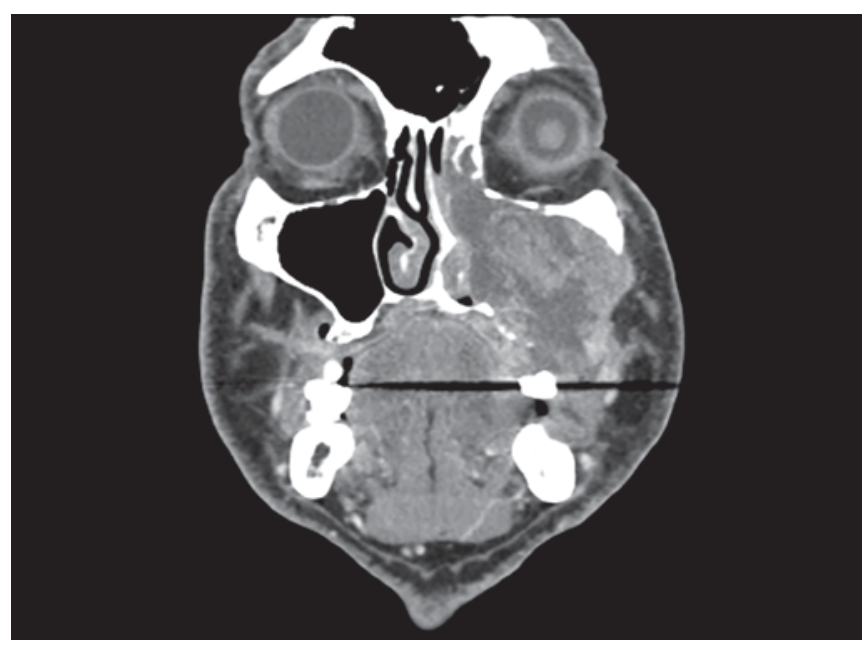

Fig. 4: Coronal CT demonstrating the lesion expansion into the nasal cavity, buccal space and hard palate region

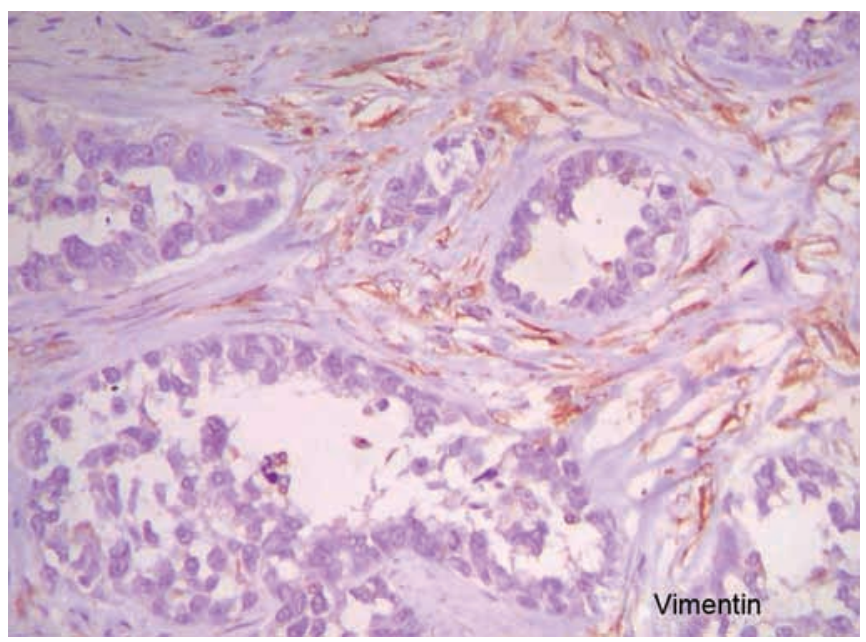

Fig. 6: Vimentin stain

Carcinosarcoma is associated with snuff use, alcohol consumption, poor oral hygiene and exposure to radiation. It was first described by Virchow in the year $1864 .^{1,2,7}$ Several theories have been postulated to explain 


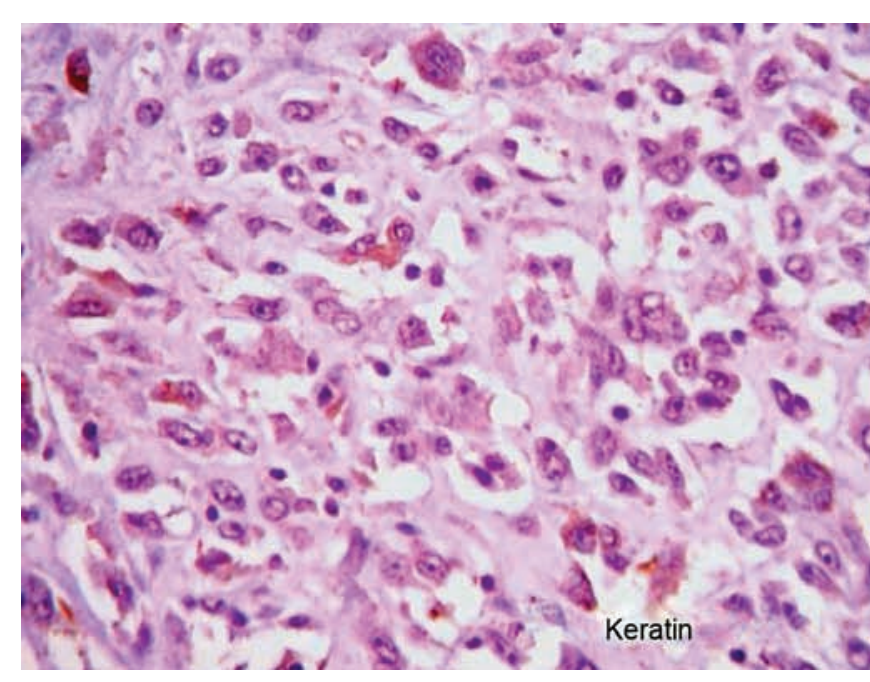

Fig. 7: Keratin stain

its origin but most believe that a multipotential cell, capable of both epithelial and mesenchymal differentiation are responsible for the origin of this rare tumor. ${ }^{1,9}$ This is a divergent differentiation of a single stem cell into epithelial and mesenchymal elements known as the monoclonal hypothesis. ${ }^{1,5,9-16,20}$ Convergent differentiation suggests this happens from two-cell lines known as the multiclonal hypothesis. $5,14,16$

A well-accepted theory of the etiology is given by the transformation of carcinoma into sarcoma, as there is evidence that these lesions are originally epithelial and then acquire a potential to express a mesenchymal phenotype. ${ }^{1}$ In the head and neck CCS involve mainly the salivary glands, parotid gland, larynx and the esophagus less frequently. Ultimately, it affects the oral cavity in the following descending order, the lips, tongue and gingiva. Carcinosarcoma has also been reported in the thyroid, thymus, lung, breast, gastrointestinal tract, hepatobiliary system, genitourinary tract, uterus and skin. 2,5,7,13,16-18

The onset of signs and symptoms of CCS manifest quickly. In the maxillary region, patients experience localized pain, tooth mobility and burning sensation. As the tumor infiltrates the maxillary sinus, patients usually experience nasal congestion as the tumor obstructs the affected sinuses. In addition, the infraorbital nerve becomes affected causing sensory disturbances on the cheek. As the tumor progresses to the skull and reaches the floor of the orbit, it presses on the eyeball creating difficulty with mobility and its position in the orbital cavity. Also, it usually invades the ethmoidal area. ${ }^{2,14,19}$ The macroscopy usually shows a polypoid mass while the histology shows epithelioid (squamous) cells with pleomorphism and spindle cells arranged in nodular aggregates with central necrosis, cellular atypia and irregular hyperchromatic nuclei. ${ }^{1,2,14}$ Immunohistochemical examination results in the expression of vimentin and keratin in epithelial cells. ${ }^{1,2,5,8,13,14,16,17,20}$ Positive cytokeratin helps to establish the diagnosis of CCS. ${ }^{1}$ Negative expression for smooth muscle actin has also been reported ${ }^{5,14}$ Regardless of treatment, CCS of the maxillary region tends to be aggressive with a high rate of recurrence. ${ }^{18,21}$

The treatment of choice consists of surgical resection combined with adjuvant radiotherapy and chemotherapy. Reconstruction with the use of prosthesis to replace the resected tissue or tissue transfer is sometimes performed
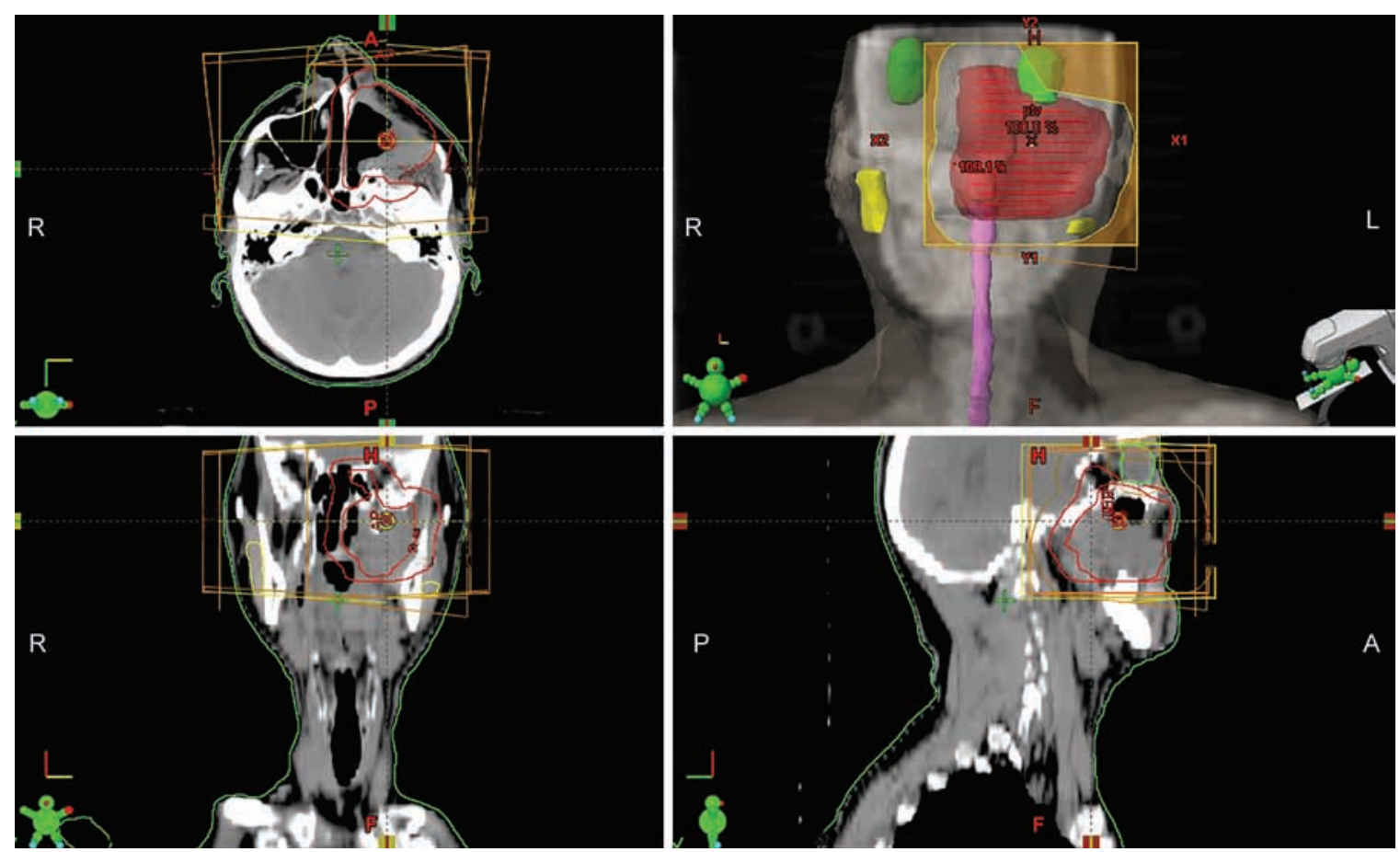

Fig. 8: Tridimensional conformal radiation plan 
depending on the extent of the surgery. ${ }^{2,5,14-17,19-21}$ Based on the stage of tumor, the 5 years survival rate ranges from 40 to $60 \% .16,19$ Metastases to the lung occurs in 5\% of cases and it has also been found in the brain, subcutaneous tissues, lymph nodes, pleura, diaphragm, bone and liver. ${ }^{1,5}$

The prognosis is determined by the size, location, morphology, depth, presence of metastases, recurrence and prior treatment; however, it is very unfavorable regardless of treatment. ${ }^{1,2,16}$

\section{CONCLUSION}

Carcinosarcoma is a rare and aggressive biphasic entity, with malignant epithelial (carcinomatous) and mesenchymal (sarcomatous) components. Imaginology is very important for diagnosis and planning treatment giving value information about growing pattern and extention to critical anatomic organs. The treatment of choice instead of scant literature, might consist of surgical resection combined with adjuvant radiotherapy and chemotherapy.

\section{REFERENCES}

1. Luizzi J, Pezzetti 1, Brito E, Garriga E, Gonzalez C. Carcinoma sarcomatoide de hipofaringe: reporte de un caso. Revista Venezolana de Oncología 2006;18(3):171-176.

2. Thompson L. Squamous cell carcinoma variants of the head and neck. Current Diagnostic Pathol 2003;9(6):384-396.

3. Rapidis A, Gakiopoulou H, Stavrianos S, Vilos G, Faratzis G. Douzinas E, et al. Sarcomas of the head and neck. Results from the treatment of 25 patients. EJSO 2005;31(2):177-182.

4. Attar E, Dey S, Hablas A, Seifeldin I, Ramadan M, Rozek L, et al. Head and neck cancer in a developing country: a population-based perspective across 8 years. Oral Oncol 2010;46(8):591-596.

5. Prakalapakorn S, Bernardino C, Auclair P. Carcinosarcoma of the orbit: report of two cases and review of the literature. Ophthalmol 2008;115(11):2065-2070.

6. Giuffrida D, Attard M, Marasa I, Ferrau F, Marietta F, Restuccia $\mathrm{N}$, et al. Thyroid carcinosarcoma, a rare and aggressive histotype: a case report. Annals of Oncology 2000;11(11): 1497-1499.

7. Rao M, Lotuaco L, Mcgregor D. Carcinosarcoma of the adult kidney. Postgraduate Med J 1977;53(622):408-411.

8. Anderson C, Al-Nafussi A. Spindle cell lesions of the head and neck: an overview and diagnostic approach. Diagnostic Histopathology 2009;15(5):264-272.

9. Okabayashi T, Sun Z, Montgomery R, Hanazaki Z. Surgical outcome of carcinosarcoma of the gall bladder: a review. World J Gastroenterol 2009;15(39):4877-4882.

10. Yamamoto $Y$, Ojima H, Shimada K, Onaya H, Hiraoka N, Mizuguchi $Y$, et al. Long-term recurrence-free survival in a patient with primary hepatic carcinosarcoma: case report with a literature review. JPN J Clin Oncol 2010;40(2):166-173.

11. Ishiwata I, Ishiwata C, Nagayama T, et al. Histogenesis and culture of human uterine carcinosarcoma. Cancer Res 1981; 41(11):1978-1983.

12. Kumar S, Perry F, Breaux G. So-called 'Carcinosarcoma' of the esophagus. J National Med Associat 1968;60(6):505-507.

13. Stojadinovic S, Reinert S, Philippou St TS, Machtens E. Carcinosarcoma of the mandibular mucosa: the first report. Int J Oral Maxillofac Surg 2002;31(4):444-447.

14. Kumar M, Goyal S, Bahl A, Das P, Sharma D, Ray R, Rath G. Sarcomatoid carcinoma of the maxillary sinus: a rare head and neck tumor. J Cancer Res Ther 2008:4(3):131-133.

15. Goto T, Maeshima A, Tajima A, Kato R. A resected case of pulmonary carcinosarcoma. Ann Thorac Cardiovasc Surg 2010;16(3):190-193.

16. Miyajima Y, Onizawa K, Kamma H, Yoshida H. Carcinosarcoma of the tongue. Oral Oncology EXTRA 2006;42(2):78-81.

17. Fan K, Connor S, MacBean A, Langdon J. MRI findings of carcinosarcoma in the parotid gland. Oral Oncol 2006;42(3): 323-326.

18. Arcas A, Gonzakz-Lagunm J, Huguet P, Raspall G. Carcinosarcoma of the maxillary sinus: a case report. J Oral Maxillofac Surg 1998;56(22):1456-1460.

19. Mehanna P, Smith G. Maxillary carcinoma a wolf in sheep's clothing. Canadian Family Physician 2009;55(3):262-264.

20. Xu F, Huang $Y$, Yang J. Primary retroperitoneal carcinosarcoma in a child: a case report. World J Surg Oncol 2010;8(99).

21. Owaki S, Kitano H, Hanada M, Asada Y, Sugihara H, Moritani $S$, et al. Carcinosarcoma of the submandibular gland: an autopsy case. Auris Nasus Larynx 2003;30(4):439-442. 